\title{
MICROBIAL TRIGGERED COLON TARGETED COMPRESSION COATED TABLETS OF TENOXICAM: FORMULATION AND EVALUATION
}

\author{
*Vagare Rupali, Doijad Rajendra, Shete Amol, Jagtap Rajesh, Mohite Poonam and Sajane Sachin \\ Research Group Department of pharmaceutics and Quality Assurance, Shree Santkrupa College of Pharmacy, \\ Ghogaon, Karad-415111, India \\ *Corresponding Author's Email: rupalivagare@gmail.com
}

Received 19 Dec 2014; Review Completed 11 Jan 2015; Accepted 13 Jan 2015, Available online 15 Jan 2015

\begin{abstract}
The present investigation deals with to formulation and evaluation of colon specific drug delivery system of Tenoxicam by compression coated tablet technique. Tenoxicam, Avicel pH101, HPMC K4M, Guar gum were used as components. Tenoxicam compression coated tablets were prepared and evaluated for differential scanning colorimetry (DSC), FTIR spectroscopy and in-vitro dissolution study without rat caecal content and with rat caecal content. The results suggest that Colon specific drug delivery system of Tenoxicam compression coated tablets were formulated successfully by using natural polymer such as Guar gum in combination with different concentration of HPMC. Tablets were evaluated for drug content, hardness, thickness, friability, weight variation, in-vitro dissolution and all the results were found within the specification. As the concentration of HPMC in compression coat increased, drug release was decreased. Based on in-vitro drug release study, it was concluded that compression coated tablets with combination of $90 \%$ Guar gum and 10\% HPMC could produce a successful drug targeting to the colon with minimal amount released in the stomach and small intestine for tenoxicam.
\end{abstract}

Keywords: Tenoxicam, Guar gum, HPMC K4M, compression coated tablet.

\section{INTRODUCTION}

Solid oral dosage forms has been one of the most suitable and widely accepted by the patient for the delivery of therapeutic active drug ${ }^{1}$. The conventional tablet dosage form provides minimal amount of drug in the colon with undesirable adverse effect due to variation in the transit time. Hence, to target the drug directly to the site of action in the colon, there is need to develop colon targeted drug delivery systems that will enhance the therapeutic drug level, increases the bioavailability of active medicament and reduce the dose of drug ${ }^{2}$.

Targeting of drugs to colon is effective and safe for the treatment of various colonic diseases like irritable bowel disease (IBD), intestinal amoebiasis, constipation, Crohn's disease, ulcerative colitis, carcinomas and infections etc ${ }^{[5]}$. At present these disease are often poorly $\&$ inefficiently managed either by oral route, in which oral drugs are largely absorbed before they rich the colon or by rectal route of administration which is less acceptable. The colon specific drug delivery system (CDDS) should be capable of protecting the drug up to rich the colon i.e., drug release \& absorption should not occur in the stomach as well as the small intestine \& neither the bioactive agent should be degraded in either of dissolution site but only released $\&$ absorbed once the system reaches the colon ${ }^{2}$. Absorption and degradation of the active ingredient in the upper part of GIT is the (c) 2011-14, JDDT. All Rights Reserved major problem with the delivery of drugs by the oral route and must be overcome for successful colonic drug delivery.

Time dependent, $\mathrm{pH}$ dependent, microbiologically controlled, multiparticulate and luminal pressure controlled system are the latest approaches of drug delivery to the colon ${ }^{3}$. However, a disadvantage of $\mathrm{pH}$ dependent system is that a substantial amount of drug may be released in the small intestine before the delivery system arrives in the colon and limitation of time dependent release system is that they are not able to sense any variation in the upper GIT transit time.

Hence, Microbial triggered delivery system is most convenient and highly site specific approach for targeting drug to colon than all targeting system. Drug releases when the polysaccharides are degraded by the bacteria of colonic microflora. Different polysaccharides have been reported for colon targeting as carriers. Most commonly used polysaccharides are guar gum, chitosan, pectin and xanthan gum etc ${ }^{2,4,6,7}$. In compression coated tablets drug present in inner core, surrounded by outer layer which contain polymer and other excipients. Outer coat degraded only in the colonic region by bacterial enzymes and subsequent drug releases in colon.

Tenoxicam chemically 4 -hydroxy $-2-$ methyl $-\mathrm{n}$ (pyridinyl-2-yl) -2h-thieno [2, 3-e]-1,2-thiazine-3ISSN: 2250-1177
CODEN (USA): JDDTAO 
carboxamide1, 1-dioxide, a Non steroidal antiinflammatory drug. It is used to relieve inflammation, swelling, stiffness ${ }^{8,9,10}$ i.e. it is used to relieve pain and inflammation of inflammatory bowel disease, ulcerative colitis, chron's disease and rheumatic arthritis. The dose of Tenoxicam is $10-20 \mathrm{mg}$ daily by mouth. Tenoxicam is completely absorbed after oral administration ${ }^{12}$. Tenoxicam has long elimination half life (60-75hr). For colon targeted drug delivery drug has good absorption and solubility profile in colon.

Tenoxicam works by blocking the action of a substance in the body called cyclo-oxygenase (COX). COX is involved in the production of various chemicals in the body, some of which are known as prostaglandins. Prostaglandins are produced by the body in response to injury and certain diseases and conditions and cause pain, swelling and inflammation. Tenoxicam blocks the production of these prostaglandins and is therefore effective at reducing inflammation and pain ${ }^{11}$.

The aim of present investigation was to use the inexpensive, naturally and abundantly available polysaccharide such as guar gum for colon targeted drug delivery. Guar gum is natural non-ionic polysaccharides derived from seeds of Cyamopsis tetragonolobus (family: leguminaciae). It consists of linear chains of $(1 \rightarrow 4)-\beta$-D-mannopyranosyl units with $\alpha$-D-galactopyranosyl units attached by $(1 \rightarrow 6)$ linkage. Cross linked guar-gum has been used as a drug carrier in matrix tablets. It was concluded that guar-gum is suitable for preparation of colon specific formulations and is suitable as a carrier for drug that are not soluble in water ${ }^{4,13,14}$. In this study, Hydroxyl Propyl Methyl Cellulose (HPMC) in combination with Guar gum was used to develop colonic delivery of Tenoxicam. HPMC was used to modify the drug release and improve the mechanical properties such as hardness of compression coated tablets.

The present investigation deals with development of microbial triggered systems for delivering Tenoxicam into the colon and provided "proof of concept" data for natural polysaccharides preparations designed for colonic drug delivery.

\section{MATERIAL AND METHODS}

Tenoxicam was a gift sample from Ramdev Chemicals, Mumbai, India, Avicel pH101, HPMC K4M and Guar gum etc. procured from Loba Chemicals, Mumbai, India. All other ingredients were of analytical grade

\section{Infrared Spectroscopy of drug ${ }^{17}$ :}

The drug-excipient interaction study was carried out by using Infrared Spectroscopy. FTIR study was carried out to check compatibility of drugs with excipient. IR spectrum of drugs, physical mixture and optimized formulation were determined on Fourier Transform Infrared spectrophotometer (FTIR, Alpha-E, and Bruker). The base line correction was done then spectrum was run.

\section{DSC of Pure Drug ${ }^{18}$ :}

The drug-polymers compatibility was confirmed by differential scanning calorimetric (DSC), which was carried out by heating drug, and the formulated drug formulations separately from $0^{\circ} \mathrm{C}$ to $300^{\circ} \mathrm{C}$ at the heating rate of $10^{\circ} \mathrm{C} / \mathrm{min}$ in a nitrogen environment of flow rate $20.0 \mathrm{ml} / \mathrm{min}$. Aluminium pans and lids were used and temperature calibrations were performed periodically using melting transition of indium as standard. Sample size of $7.5 \mathrm{mg}$ used for analysis. The instrument used was SDT Q600 V20.9 Build 100 differential scanning calorimeter with Universal V4.5 software.

\section{Preparation of Tenoxicam core Tablets:}

The core tablets of Tenoxicam for compression coating were prepared by direct compression technique. Each core tablet $(50 \mathrm{mg})$ consist of $10 \mathrm{mg}$ tenoxicam, 39.50 mg Avicel PH101, and $0.5 \mathrm{mg}$ magnesium stearate. The powders were thoroughly mixed and passed through mesh $(60 \mu \mathrm{m})$. The uniformity of mixing was assessed by conducting content uniformity tests on the samples of powder mix. The mixture was compressed into tablets using $\mathrm{KBr}$ press with an applied force of 500 $\mathrm{kg} / \mathrm{cm}^{-1}$ using $4 \mathrm{~mm}$ round, Flat punch. The thickness and crushing strength of core tablets were measured.

\section{Compression coating of Tenoxicam core tablets:}

The coating materials of $150 \mathrm{mg}$ Guar Gum in combination with 10\%, 20\%, and 30\% HPMC respectively were used to prepare coats respectively as shown in table 1 . Half the amount of compression coating material was placed in the die cavity followed by carefully centering the core tablet and addition of the remaining coat weight. The coating material was then compressed around the core tablets using $\mathrm{KBr}$ press at an applied force of $1500 \mathrm{~kg} / \mathrm{cm}^{-}{ }^{1}$ using $8 \mathrm{~mm}$ round, flat punch. The prepared tablets were tested for the uniformity of weight, drug content, mechanical properties (hardness and friability) and drug release characteristics. The strength of compression coat tablet was determined.

Table 1: Composition of Guar Gum and HPMC used to cover Tenoxicam core tablets

\begin{tabular}{|c|c|c|c|}
\hline \multirow{2}{*}{ Formulation code } & \multirow{2}{*}{$\begin{array}{c}\text { Coat weight } \\
\text { (mg) }\end{array}$} & \multicolumn{2}{|c|}{ Content (mg) } \\
\cline { 3 - 4 } & & Guar Gum & HPMC \\
\hline $\mathrm{F}_{1}$ & 150 & 135 & 15 \\
\hline $\mathrm{F}_{2}$ & 150 & 120 & 30 \\
\hline $\mathrm{F}_{3}$ & 150 & 105 & 45 \\
\hline
\end{tabular}




\section{Characterization of Tenoxicam compression coated tablets $^{20,21,22}$ :}

The prepared tablets were evaluated for weight variation, hardness, friability and drug content

\section{Swelling study:}

Initial diameter, height and weight of individual matrices $\left(\mathrm{S}_{0}\right)$ were measured and were placed in a dissolution medium (Phosphate buffer pH 6.8) at $37 \pm 0.5^{\circ} \mathrm{C}$. Swollen tablets after specific time intervals $(3,6,9,12$ and 24) were withdrawn from the medium, extra buffer present on the matrix surface was gently wiped with the soft tissue and individual diameter, height and weight $\left(\mathrm{S}_{1}\right)$ were measured at predetermined time intervals. Percent of the radial (diameter) and axial (height) swelling of tablet and percent water uptake was calculated according to the following formula ${ }^{29}$.

$$
\text { Percent swelling }(\mathrm{Sw})=\left[\left(\mathrm{S}_{1}-\mathrm{S}_{0}\right) / \mathrm{S}_{0}\right] \times 100
$$

Where, S1 and S0 are the diameter or height of swollen tablets respectively. The percentage swelling of the original tablet was calculated and plotted vs. Time.

\section{Preparation of rat caecal content ${ }^{25}$ :}

Committee for the Purpose of Control and Supervision of Experiments of Animals (CPCSEA).The Institutional Animal Ethical Committee (IAEC) of Tatyasaheb College of Pharmacy, Warananagar, Maharashtra, India has approved the experimental protocols for this work (IAEC/TKCP/2014/14).

The caecal contents were obtained from Wistar rats weighing $150-200 \mathrm{~g}$, after pre-treatment with oral administration of $2 \mathrm{~mL}$ of $1 \% \mathrm{w} / \mathrm{v}$ of polymer dispersion (i.e. Guar gum) in water for 3 days. Thirty minutes before starting drug release studies, each rat was killed by spinal traction, after which abdomens were opened, dissected, and immediately transferred to $\mathrm{pH} 6.8$ phosphate buffer previously bubbled with $\mathrm{CO} 2$. The caecal bags were then opened; their contents were individually weighed, homogenized, and then suspended in $\mathrm{pH} 6.8$ phosphate buffer to give the desired concentration of $2 \%(\mathrm{w} / \mathrm{v})$ of caecal content. As the caecum is naturally anaerobic, all these operations were carried out under $\mathrm{CO}_{2}$.

\section{In vitro drug release studies:}

The ability of the prepared tablets to retard drug release in the physiological environment of the stomach and small intestine was assessed by conducting drug release studies in stomach and small intestine $\mathrm{pH}$, respectively. Dissolution test was conducted in USP I apparatus at 100 rpm and a temperature of $37 \pm 0.5^{\circ} \mathrm{C}$. The tablets were tested for drug release for 2 hours in acidic buffer of $\mathrm{pH}$ $1.2(900 \mathrm{ml}), \mathrm{pH} 7.4$ phosphate buffer for 3 hours and phosphate buffer $\mathrm{pH} 6.8$ for 19 hours with or without rat caecum content. $5 \mathrm{ml}$ of each sample was withdrawn at $1,2,3,4,5,6,8,10,12,16,20$, and $24 \mathrm{hrs}$ time and replaced with an equal volume of fresh media. The content of tenoxicam in the withdrawn samples was analyzed spectrophotometerically ${ }^{30}$.

\section{Release kinetics:}

Data obtained from the in-vitro release studies of compression coated tablet of Tenoxicam formulations, were fitted to various kinetic equations such as zero order, first order, Higuchi model, Korsmeyer-Peppas model $^{24}$

\section{Stability Studies:}

The optimized formulation was subjected for one month stability study at room temperature. The selected formulations were packed in aluminium foil in tightly closed Container. Formulations were stored at room temperature for one month. After one month interval, placed sample were analyzed for physical appearance, Drug content, in-vitro dissolution study, Hardness, thickness.

\section{RESULTS AND DISCUSSION}

\section{Drug -excipients compatibility study:}

The overlay of IR spectrum of drug and physical mixture is shown in Figure 1 and table 2, which shows that peaks observed in spectrum of pure drug at wave number $1144 \mathrm{~cm}^{-1}, 1199 \mathrm{~cm}^{-1}, 1388 \mathrm{~cm}^{-1}, 1420 \mathrm{~cm}^{-1}, 1493 \mathrm{~cm}$ 1 were also observed in spectrum of physical mixture. No significant changes in peak pattern in the IR spectra of pure Drug and physical mixture indicates that there is no interaction between pure drug and polymer.

Table 2: Comparative FTIR Study of drug and polymer

\begin{tabular}{|l|l|l|l|l|l|}
\hline \multicolumn{1}{|c|}{$\begin{array}{c}\text { Name of } \\
\text { Compound }\end{array}$} & C-O stretching & \multicolumn{1}{|c|}{$\begin{array}{c}\text {-O-H } \\
\text { bending }\end{array}$} & $\begin{array}{c}\mathbf{C H}_{3} \\
\text { deformation }\end{array}$ & $\begin{array}{c}\text { Heterocyclic } \\
\text { ring }\end{array}$ & -C-H deformation \\
\hline Tenoxicam & $1144 \mathrm{~cm}^{-1}$ & $1199 \mathrm{~cm}^{-1}$ & $1388 \mathrm{~cm}^{-1}$ & $1420 \mathrm{~cm}^{-1}$ & $1493 \mathrm{~cm}^{-1}$ \\
\hline $\begin{array}{l}\text { Tenoxicam and } \\
\text { HPMC }\end{array}$ & $1142 \mathrm{~cm}^{-1}$ & $1199 \mathrm{~cm}^{-1}$ & $1385 \mathrm{~cm}^{-1}$ & $1420 \mathrm{~cm}^{-1}$ & $1492 \mathrm{~cm}^{-1}$ \\
\hline $\begin{array}{l}\text { Tenoxicam and } \\
\text { Guar Gum }\end{array}$ & $1144 \mathrm{~cm}^{-1}$ & $1199 \mathrm{~cm}^{-1}$ & $1387 \mathrm{~cm}^{-1}$ & $1420 \mathrm{~cm}^{-1}$ & $1493 \mathrm{~cm}^{-1}$ \\
\hline $\begin{array}{l}\text { Physical mixture of } \\
\text { all ingredients }\end{array}$ & $1442 \mathrm{~cm}^{-1}$ & $1190 \mathrm{~cm}^{-1}$ & $1387 \mathrm{~cm}^{-1}$ & $1418 \mathrm{~cm}^{-1}$ & $1491 \mathrm{~cm}^{-1}$ \\
\hline
\end{tabular}




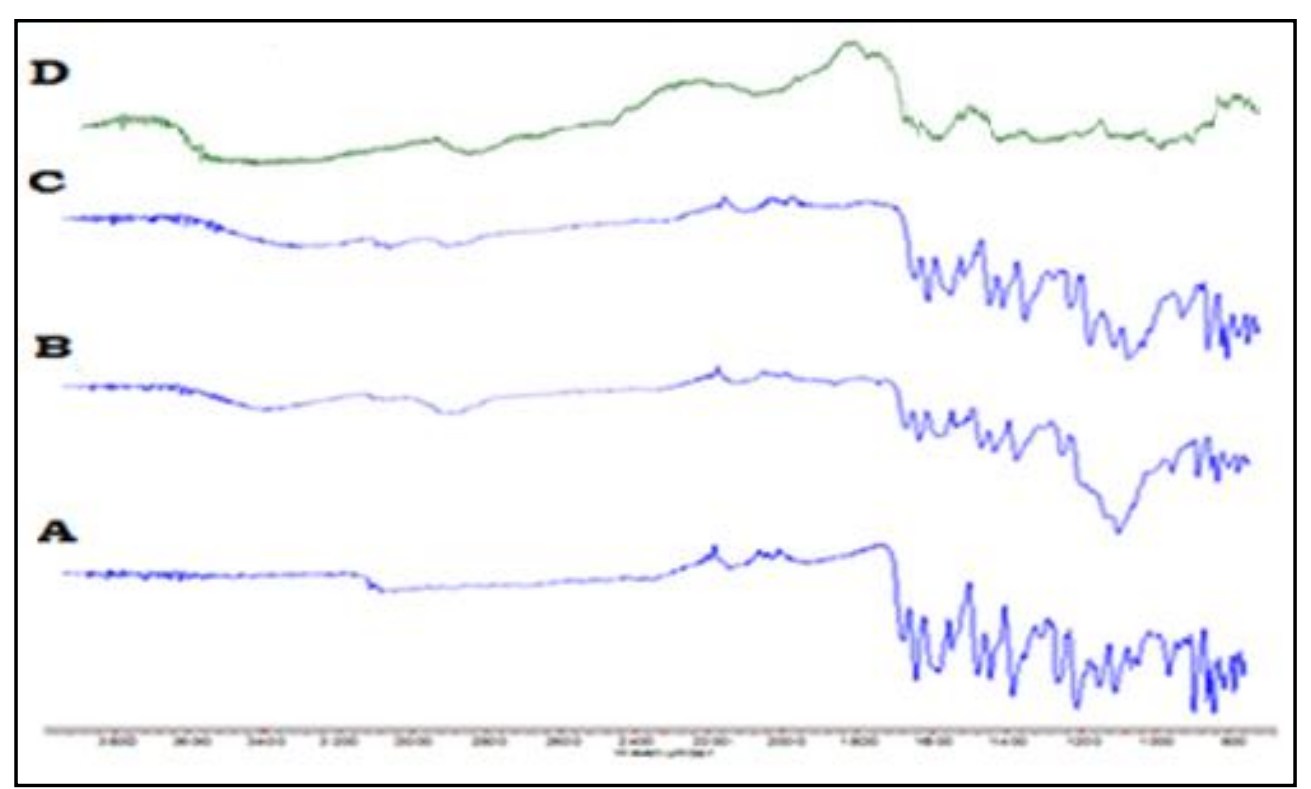

Figure 1: Overlay of FTIR spectrum of (A) Tenoxicam (B) Physical mixture of Tenoxicam and HPMC K4M (C) Physical mixture of Tenoxicam and Guar Gum (D) Physical mixture of all ingredients.

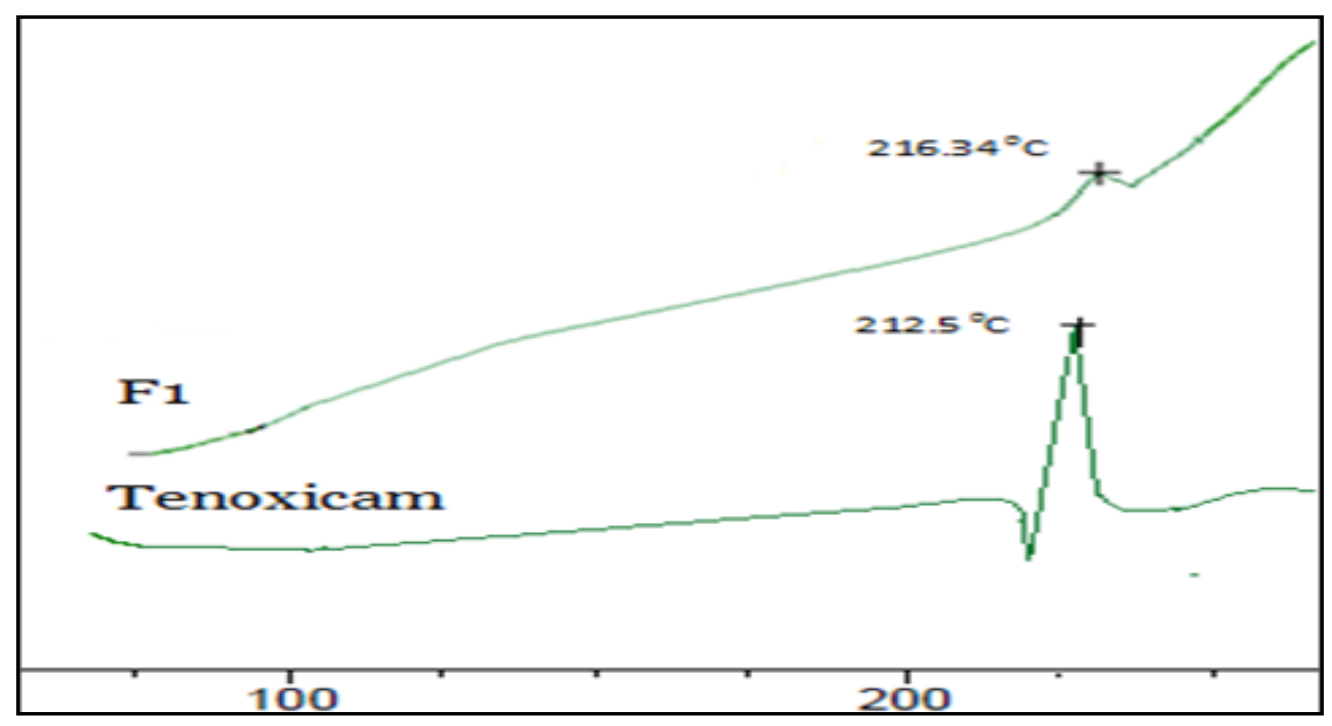

Figure 2: Overlay of DSC Thermogram of (A) Tenoxicam (B) Optimized formulation $\mathbf{F}_{1}$

Figure 2 shows the DSC thermographs of pure drug Tenoxicam and formulation $\mathrm{F}_{1}$. Thermographs obtained by DSC studies, revealed that the DSC thermogram of the drugs depicts a sharp exothermic peak at $212.5^{\circ} \mathrm{C}$ reflects the pure crystalline state of the drug and that of the drug in the formulation $\mathrm{F}_{1}$ depicts a exothermic peak at $216.34^{\circ} \mathrm{C}$ with marked decrease in sharpness. The sharpness of peak in formulation $F_{1}$ decreased due to low concentration of Tenoxicam drug in formulation i.e. due to dilution of drug. As there is no much difference in the melting point of the drug in the thermograms of drug and that of in the formulation $F_{1}$. It may be concluded that, the drug was in the same pure state even in the formulation without interacting with the polymers 18 .

\section{Physical properties of tablets:}

The hardness of prepared tablets was found to be in the range of $5.30 \pm 0.11$ to $6.02 \pm 0.38 \mathrm{~kg} / \mathrm{cm}^{2}$, a value which indicates good strength. Thickness of all tablets was found to be in the range of $2.13 \pm 0.05$ to $2.23 \pm 0.5 \mathrm{~mm}$. For weight variation test, the Pharmacopoeial limit for percent deviation for tablets weighing up to $250 \mathrm{mg}$ is not more than $7.5 \%$. The average percent deviation of all tablets was found to be within the limit; hence all formulation passes the weight variation test. The values of friability for all these formulations were less than the limit of $1 \%$ which is given in the IP. The friability was found in these formulations shows a good strength of tablets to withstand abrasion during transportation and general handling. Drug content of core tablet was found to be $101.17 \pm 0.20 \%$. As per the IP specification drug content for tablets must be in the range of 85 to $115 \%$. Thus, formulation passes the uniformity of drug content test as shown in table 3 . 
Table 3: Physical properties of compression coated tablets of Tenoxicam

\begin{tabular}{|c|c|c|c|c|c|}
\hline \multirow{2}{*}{ Batch code } & \multicolumn{5}{|c|}{ Parameter } \\
\cline { 2 - 6 } & $\begin{array}{c}\text { Diameter } \\
(\mathbf{m m} \pm \mathbf{S D}) \mathbf{a}\end{array}$ & $\begin{array}{c}\text { Thickness } \\
(\mathbf{m m} \mathbf{+ S D}) \mathbf{b}\end{array}$ & $\begin{array}{c}\text { Hardness } \\
(\mathbf{k g} / \mathbf{c m} \mathbf{\text { Sm}}) \mathbf{c}\end{array}$ & $\begin{array}{c}\text { Friability } \\
(\boldsymbol{\%} \pm \mathbf{S D}) \mathbf{d}\end{array}$ & $\begin{array}{c}\text { Weight variation } \\
(\boldsymbol{\%}) \mathbf{e}\end{array}$ \\
\hline $\mathrm{F}_{1}$ & $8.2 \pm 0.23$ & $2.16 \pm 0.1$ & $5.30 \pm 0.11$ & $0.41 \pm 0.12$ & 2 \\
\hline $\mathrm{F}_{2}$ & $8.2 \pm 0.17$ & $2.23 \pm 0.5$ & $5.50 \pm 0.11$ & $0.33 \pm 0.5$ & 1 \\
\hline $\mathrm{F}_{3}$ & $8.3 \pm 0.32$ & $2.13 \pm 0.05$ & $6.02 \pm 0.38$ & $0.26 \pm 0.15$ & 0.5 \\
\hline
\end{tabular}

\section{Swelling studies:}

Measurement of swelling rates of different matrices were carried out to gain insight into the observed phenomena of drug release with the rates of polymer hydration and to evaluate the extent of water penetration into the tablets. The graphs of water uptake, axial and radial expansion for $F_{1}$ are enumerated in Figure 3. It is evident that water uptake was continuously rising throughout the study. This supports the observation that the diffusion was predominant. Figure 3 shows the results of water uptake, axial and radial expansion for formulation $\mathrm{F} 1$. Though water uptake was continuously increasing with time, the radial and axial expansion was almost constant after $12 \mathrm{hr}$. This suggests the role of erosion to maintain constant diffusional path length because of proper synchronization between erosion and diffusion ${ }^{29}$.

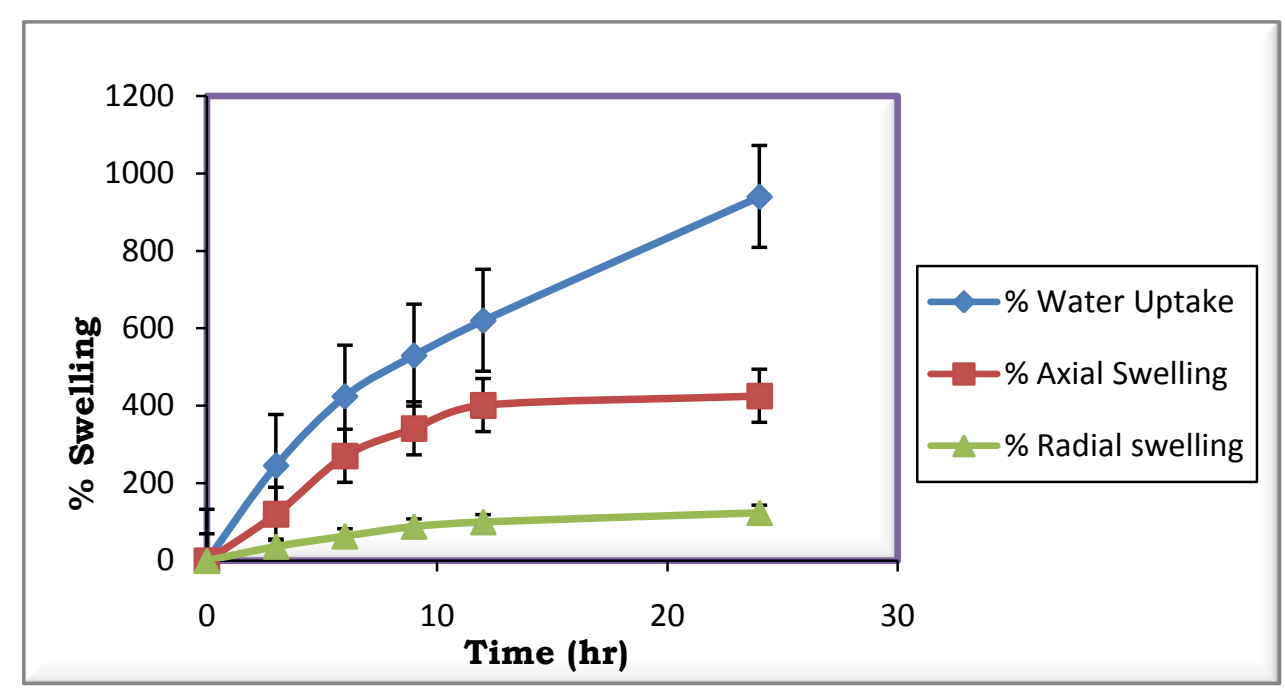

Figure 3: Swelling study of formulation $\mathrm{F}_{1}$ including $\%$ water uptake, $\%$ axial swelling, $\%$ radial Swelling.

\section{In-vitro drug release studies:}

The mean drug release from the tablets $\mathrm{F}_{1}, \mathrm{~F}_{2}, \mathrm{~F}_{3}$ after the first $5 \mathrm{hr}$ was $8.21 \pm 0.15 \%, 8.63 \pm 0.3 \%$ and $8.07 \pm 0.3 \%$ respectively. At the end of $24 \mathrm{hr}$, the mean $\%$ drug release was $40.58 \pm 0.12 \%, 36.13 \pm 0.3 \%$ and $27.72 \pm 0.15 \%$. As the concentration of HPMC increased, drug release was decreased. The increase in drug release could be explained due to HPMC creates a porous structure of the coat and consequently increases Guar Gum leaching and drug released. However further increase in HPMC \% to $20 \%$ and $30 \%$ of the compression coat caused a reduction in gum leaching, with a consequent decrease in drug release as shown in Figure 4. Higher concentration of HPMC would reduce the free water volume and increase the viscosity of the coat causing a reduction in the polymer leaching and subsequent reduction in drug release ${ }^{[25]}$. Based on these results, $F_{1}$ batch optimized for further in-vitro dissolution study using rat caecal content. Since, the \% drug release at the end of $5 \mathrm{hr}$ which was expected time for the arrival of dosage form in the colon was found to be $8.21 \pm 0.15 \%$ and $40.58 \pm 0.12 \%$ drug release was achieved after $24 \mathrm{hr}$ which is higher as compared to $\mathrm{F}_{2}$ and $\mathrm{F}_{3}$ batch. 


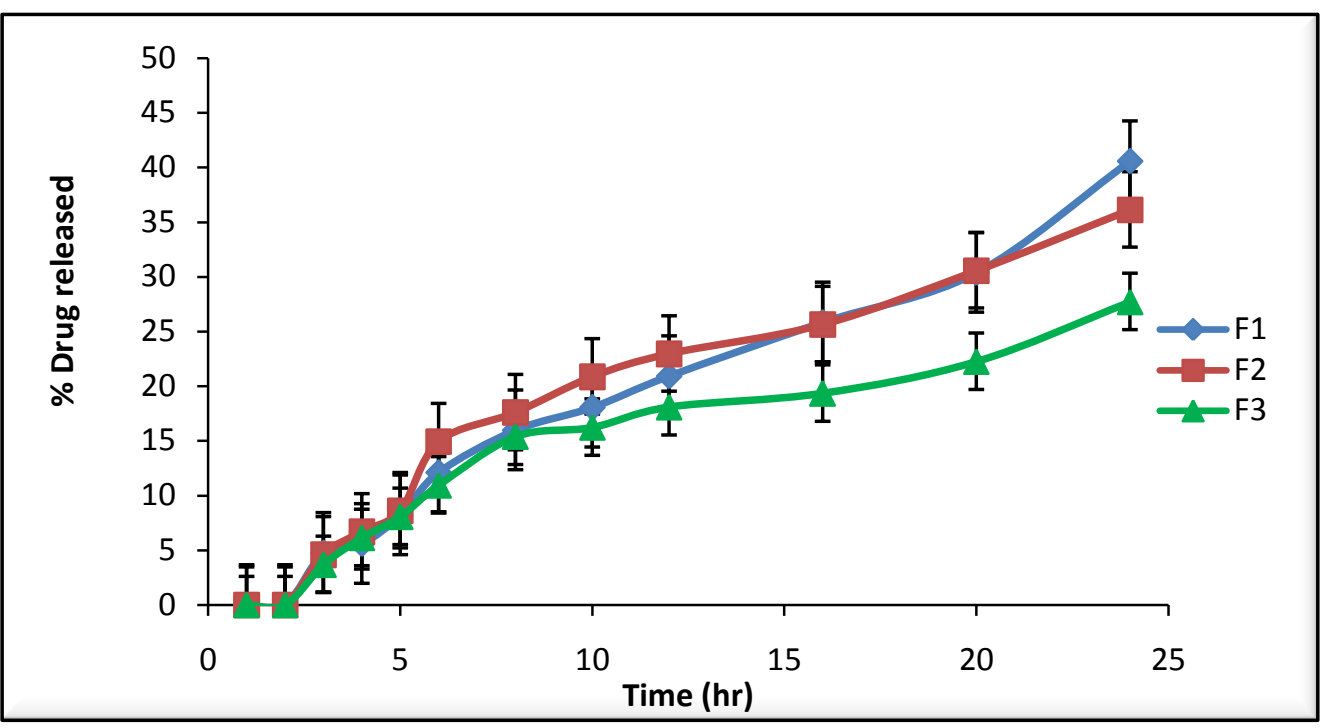

Figure 4: Release profile of Tenoxicam in formulation $F_{1}$ to $F_{3}$ without rat caecal content.

As shown in Figure 5, the mean drug release from the tablet $F_{1}$ after the first $5 \mathrm{hr}$ was $7.54 \pm 0.5 \%$. At the end of $24 \mathrm{hr}$, the mean \% drug release was $94.54 \pm 0.4 \%$ in rat caecal medium. The maximum drug release after $24 \mathrm{hr}$ in rat caecal medium was significantly higher in comparison with the drug release in control medium. This can be explained as the release of Tenoxicam in the physiological environment of colon is due to microbial degradation of Guar Gum.

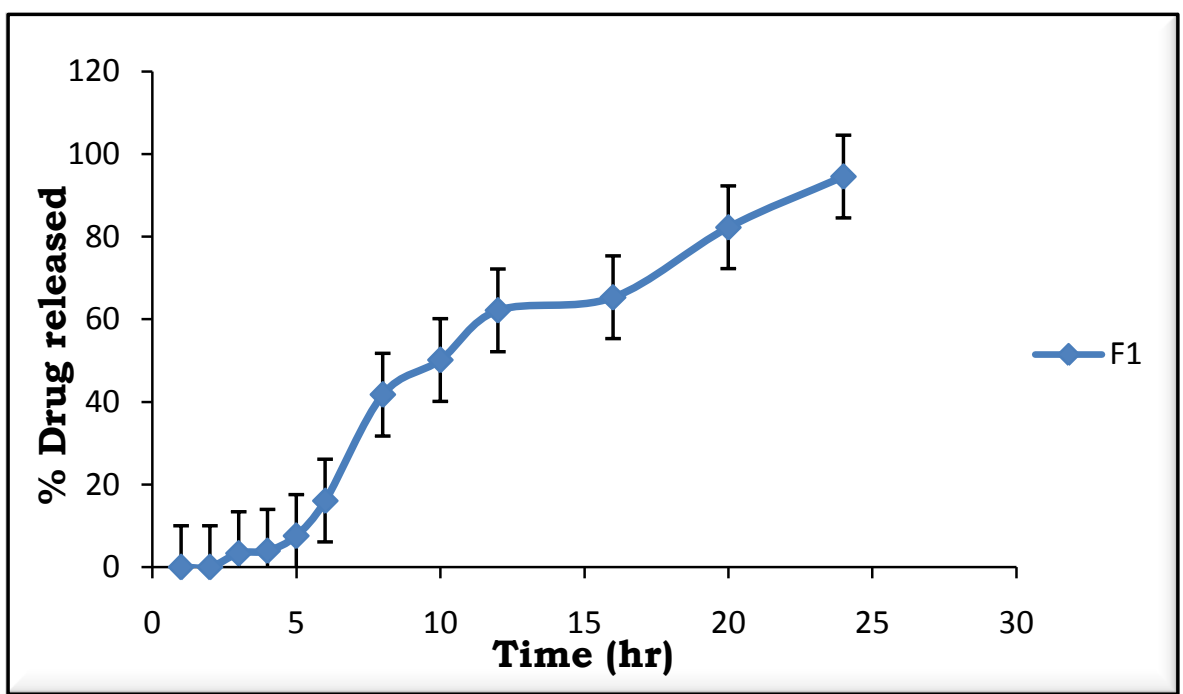

Figure 5: Release profile of Tenoxicam in formulation $F_{1}$ using rat caecal content.

\section{Drug Release Kinetics ${ }^{23,}{ }^{24}$ :}

Table 4 shows optimized batch $F_{1}$ followed Koresmeyer-Peppas model indicate significant contribution of diffusion and also showed exponent $n$ value between 0.5 and 1 which indicate non-fickian diffusion and furthermore together with the good fitting of Zero order model indicating erosion controlled release i.e. release was found to be both erosion and diffusion controlled
Table 4: Release kinetics of optimized batches

\begin{tabular}{|c|c|c|}
\hline Sr. & Models & Optimized formulation $\mathbf{F}_{\mathbf{1}}$ \\
\cline { 3 - 3 } No. & & $\mathbf{R}^{\mathbf{2}}$ \\
\hline 1 & Zero order & 0.937 \\
\hline 2 & Koresmeyer- & 0.940 \\
& Peppas & $(\mathrm{n}=0.50)$ \\
\hline 3 & First order & 0.915 \\
\hline 4 & Higuchi & 0.875 \\
\hline
\end{tabular}




\section{Stability Studies:}

Short-term stability studies were carried out on the optimized formulation F1. The tablets of optimized batch were stable for 1 month at room temperature. There was no change in the physical appearance and drug content of the tablet during storage period. Mean $( \pm$ S.D) drug content at the end of 1 month was found to be $99.21 \pm 0.5 \%$ indicating no significant change in the drug content. The \% CDR during the drug release study conducted in the 0.1N HCL, PBS pH 7.4 and PBS pH 6.8 after storage of 1 month was found to be 39.15 $0.15 \%$ indicating no significant change in the in-vitro dissolution of tablet. The results indicated that, there were no any changes observed in tablet characteristics after stability study.

\section{CONCLUSION}

Colon specific drug delivery system of Tenoxicam compression coated tablet was formulated successfully

\section{REFERENCES}

1. Verma S, Saini S, Rawat A, Kaul M. Formulation, Evaluation and Optimization of Osmotically Controlled Colon Targeted Drug Delivery System. J. Pharm. Sci. \& Res. 2011; 3(9): 1472-85.

2. Manasa B, Krishnan SK, Ahmed MG, DR. Nagesh and Ramesh B. Formulation and in- vitro evaluation of colon targeted matrix tablets of Lornoxicam. Int. J. of pharm and chemical Sci. 2013; 2(1):259-65.

3. Kaur Sukhbir, Recent approaches for colon targeted drug delivery system, ijpcbs 2013, 3(2), 360-371.

4. Bhawna G, Lovekesh N, Singh S. Formulation and Gamma Scintigraphic Evaluation of Colon Targeted Drug Delivery Systems Of Tinidazole In Healthy Human Volunteers. JPBMS. 2011;7(16):1-9.

5. Chithaluru K, Tadikonda R. Formulation and Evaluation of Microbially triggered compression coated tablets of Ketorolac Tromethiamine. Der Pharmacia Lettre. 2011: 3 (4) :29-39

6. Bali V, Pathak K, Dev RK. Novel microbially triggered colon specific delivery system of 5-Fluorouracil: Statistical optimization, in vitro, in vivo, cytotoxic and stability assessment. Int. J. of Pharmaceutics.2011; 411: 142-51.

7. Godge $\mathrm{G}$, Hiremath $\mathrm{S}$. Colonic delivery of film coated meloxicam tablets using natural polysaaaharide- polymer mixture. Int. Current Pharmaceutical journal.2012; 1(9):26471

8. Panwar MS' Goyal A. Visible Spectrophotometric Estimation of Tenoxicam from Tablets. International Journal of Pharmaceutical \& Biological Archives 2012; 3(4):993-95.

9. Merck Index, 13 edn. Merck and com. Inc, White house station, 2001, 1632.

10. "British Pharmacopoeia", Published by the deptt. Of health and stationary office under the license from the controller of her majesty; stationary office for the dept. of Health Minister, UK, 2002, 2477.

11. Mobiflex (tenoxicam)

12. Brittain HG. Analytical profile of Drug substances and excipients. 22:p.433-57.

13. Brittain HG. Analytical profile of Drug substances and excipients. 24:p.245-69.

14. Rowe RC, Sheskey PJ, Quinn ME. Handbook of pharmaceutical excipients. $6^{\text {th }}$ ed.p.298-300.

15. Merck Index, $13^{\text {th }}$ edn. Merck and com. Inc, White house station, 2001, 1632.

16. "British Pharmacopoeia", Published by the dept. Of health and stationary office under the license from the controller of by using natural polymer such as Guar gum in combination with different concentration of HPMC. Based on in-vitro drug release study, it was concluded that compression coated tablets with combination of 90\% Guar gum and 10\% HPMC could produce a successful drug targeting to the colon with minimal amount released in the stomach and small intestine.

\section{COMPETING INTERESTS}

The authors report no conflicts of interest. The authors alone are responsible for the content and writing of the paper.

\section{ACKNOWLEDGEMENT}

The authors are thankful to Ramdev Chemicals Pvt. Ltd., Thane, Maharashtra, for providing gift sample of Tenoxicam \& also thankful to the management of Shree Santkrupa College of Pharmacy, Ghogaon, Karad for providing laboratory facilities.

her majesty; stationary office for the dept. of Health Minister, UK, 2002, 2477.

17. Chatwal GR, Anand SK, Instrumental Methods of Chemical Analysis. $5^{\text {th }}$ ed. Himalaya Publishing House.2002.p. 2.29

18. Chatwal GR, Anand SK. Instrumental Methods of Chemical Analysis. $5^{\text {th }}$ ed. Himalaya Publishing House.2002.p. 2.719.

19. Pavia PL, Lampman GM, Kriz GS. Introduction to spectroscopy, $3^{\text {rd }}$ ed.2001.p. 13-101

20. Remington. The Science and Practice of pharmacy. 21st edition. Lippincott Williams and wilkins. vol I. p. 889-902.

21. Indian Pharmacopoeia. Government of India, New Delhi: Controller of Publications; 1, 2007.p.183-84.

22. The United State Pharmacopoeia, 19 (USP NF). The Official Compendia of Standards, Asian Edition, 2000.p. 1945

23. Yadav AV, Yadav VB, Shete AS. Experimental Biopharmaceutics and Pharmacokinetics. $1^{\text {st }}$ ed. Nirali Prakashan.2011.p.1.14-1.17

24. Bramhankar DM, Jaiswal SB. Biopharmaceutics and pharmacokinetics a treatise. Delhi: Vallabh Prakashan; 1995: 431-33

25. Nasr M, Hashem FM, Shaker DS, Saad IE, Ragaey R. Guar gum and hydroxy propyl methylcellulose compressed coated tablets for colonic drug delivery: in vitro and in vivo evaluation in healthy human volunteers. Drug Discoveries \& Therapeutics. 2011; 5(2):90-95.

26. Turkoglu M, Ugurlu T. In vitro evaluation of pectin-HPMC compression coated 5-aminosalicylic acid tablets for colonic delivery.European Journal of Pharmaceutics and Biopharmaceutics. 2002; 53: 65-73.

27. Ugurlu T, Turkoglu M, Gurer US, Akarsu BG. Colonic delivery of compression coated nisin tablets using pectin/HPMC polymer mixture. European Journal of Pharmaceutics and Biopharmaceutics. 2007; 67: 202-210.

28. Macleod GS, Fell JT, Collett JH, Sharma HL, Smith AM. Selective drug delivery to the colon using pectin:chitosan:hydroxypropyl methylcellulose film coated tablets. International Journal of Pharmaceutics. 1999; 187: 251-257.

29. Ebube NK, Hikal AH, Wyandt CM, Beer DC, Miller LG, Jones AB. Sustained release of acetaminophen from heterogeneous matrix tablets: influence of polymer ratio, polymer loading and co-active on drug release. Pharm. Dev. Technol. 1997; 2: 161-70.

30. Ilango KB, Manisha M, Brinda P. Investigation of Colon Specificity of Novel Polysaccharide okra Mucilage-Film Coated With Enteric Materials. Int. J. of Pharma and Bio Sci. 2012; 3(2):53-62. 